\title{
Dark Current Spectroscopy of Transition Metals in CMOS Image Sensors
}

\author{
Felice Russo, ${ }^{\text {a }}$ Giancarlo Nardone, ${ }^{\text {a }}$ Maria Luisa Polignano, ${ }^{\text {, }, z}$ Angelo D'Ercole, ${ }^{\text {a }}$ \\ Fabrizio Pennella, ${ }^{\mathrm{a}}$ Massimo Di Felice, ${ }^{\mathrm{a}}$ Andrea Del Monte, ${ }^{\mathrm{a}}$ Antonio Matarazzo, ${ }^{\mathrm{a}}$ \\ Giuseppe Moccia, ${ }^{\mathrm{a}}$ Gianpaolo Polsinelli, ${ }^{\mathrm{a}}$ Antonio D'Angelo, ${ }^{\mathrm{a}}$ Massimo Liverani, \\ and Fernanda Irrera ${ }^{c}$
}

\author{
${ }^{a}$ Lfoundry a SMIC Company, 67051 Avezzano (AQ), Italy \\ ${ }^{b}$ STMicroelectronics, 20864 Agrate Brianza (MB), Italy \\ 'Universita' La Sapienza, 00184 Rome, Italy
}

We have investigated the effects of deliberate heavy metals contamination on dark current and image defects in CMOS Image Sensors (CIS). Analysis of dark current in these imager dice has revealed different behaviors among most important $3 \mathrm{~d}$ metals present in the process line. We have implanted directly in 3 Mega array pixels the following metals: $\mathrm{Cr}, \mathrm{V}, \mathrm{Cu}, \mathrm{Ni}, \mathrm{Fe}, \mathrm{Ti}, \mathrm{Mo}, \mathrm{W}, \mathrm{Al}$ and $\mathrm{Zn}$. Analyzing the dark current "spectrum" as obtained for fixed integration periods of time by means of standard image-testing equipment, these impurities can be identified and detected with a sensitivity of $\sim 10^{9} \mathrm{traps} / \mathrm{cm}^{3}$ or higher.

(C) 2017 The Electrochemical Society. [DOI: 10.1149/2.0101705jss] All rights reserved.

Manuscript submitted January 12, 2017; revised manuscript received February 22, 2017. Published March 10, 2017.

In the last decade, CMOS Image Sensors (CIS) have been used in a wide range of applications such as the Digital Still Cameras (DSC) and cellular mobile phones having clear advantages over the Charge Coupled Devices (CCDs) in terms of low power consumption, on-chip functionality, low cost, etc. ${ }^{1}$ However, as the pixel size shrinks, the performances of semiconductor detectors and sensors are degraded by the dark current generation, due to point defects and impurities in the materials. Many metal contaminants of common use in the CMOS line process have been demonstrated to generate deep electronic levels in the silicon bandgap ${ }^{2}$ behaving as traps or generation/recombination centers. The main parameter to determine the electrical activity of those levels (traps) are the activation energy and the density ${ }^{3}$ which depend on the contaminant specie and amount. The target of the work is the identification of deep electronic levels using the Dark Current Spectroscopy (DCS) technique, in order to determine and reduce the source of such levels for minimizing the undesired electrical phenomena of dark current and image defects. The DCS was firstly developed in 1992 to determine the energy levels of contaminants in $\mathrm{CCDs}^{4}$ based on the dark current-temperature relationship. Dark current in image sensors is an undesired current created by carriers not generated by photons in the pinned photodiode. It is enhanced by individual defects such as metallic contamination dissolved in silicon, by interface states or by structural defects such as dislocation. In a pixel array, the pixels that do not contain any impurity atom will have a dark current due to the intrinsic sources common to all pixels. The pixels with an electrically active impurity inside the photodiode will exhibit an additional dark current due to the thermal generation of carriers in the pixel volume according to the SRH (Shockley-Read-Hall) recombination model. ${ }^{3}$ Since the distribution of contaminant atoms over the pixel matrix is considered random it is expected to follow a Poisson distribution. ${ }^{5}$ The dark current spectrum (see Fig. 1) then is the histogram of dark current intensity considering the whole pixel array. The DCS technique is the dark current spectrum characterization as function of temperature. The large-full-well capacities of CCDs was perfect to the purpose since deep-level traps can rapidly produce large amounts of free carriers at high temperatures. More recently, some papers reported the successful application of DCS in CIS devices, to detect Au and $\mathrm{W},{ }^{6,7}$ the relatively smallfull-well of CIS makes it more difficult to obtain accurate data of dark current.

This paper presents a systematic and deep investigation of the impact of a wide range of transition metal contaminants on CMOS image sensor performances, by the use of the dark current spectroscopy technique.

\section{Experimental}

Wafers with the following characteristics were used in this study: (100) orientation; $200 \mathrm{~mm}$ diameter and $725 \mu \mathrm{m}$ thick wafers with a $20 \Omega \mathrm{cm}$ p-type epitaxial layer grown on a $0.015 \Omega \mathrm{cm} \mathrm{p}+$ substrate with interstitial oxygen concentration in the range $20-30$ ppma (measured by Gas Fusion Analysis calibrated by Fourier Transform Infrared Spectrometry with the ASTM F121-79 standard). The n-type region of the junction was obtained by ion implantation, and the concentration in this region ranged from $10^{17} \mathrm{~cm}^{-3}$ to $10^{15} \mathrm{~cm}^{-3}$. They were contaminated implanting the following metallic elements: $\mathrm{Cr}$, $\mathrm{V}, \mathrm{Cu}, \mathrm{Ni}, \mathrm{Fe}, \mathrm{Ti}, \mathrm{Mo}, \mathrm{W}, \mathrm{Al}, \mathrm{Zn}$ directly into the photodiode. The implantation was performed on a Varian MC50 with a type II Bernas ion source with $\mathrm{W}$ arc chamber. A design of experiment (DOE) to set the implanter dose and energy for each metallic element was used. Every metallic element was implanted in a particular wafer shot each containing multiple dies as shown in the Fig. 2.

DOE energy and dose (see Table I) were chosen according to Stopping and Range of Ions in Matter (SRIM) software ${ }^{8}$ ). For each group conditions were established in order to have all the metallic contaminants inside our pinned photodiode $\mathrm{p}+/ \mathrm{n} / \mathrm{p} 1$ um deep after the implantation. SRIM software is a group of programs which calculate the stopping and range of ions (up to $2 \mathrm{GeV} / \mathrm{amu}$ ) into matter using a quantum mechanical treatment of ion-atom collisions (assuming a moving atom as an "ion", and all target atoms as "atoms"). An example for $\mathrm{W}$ is reported in the Fig 3. The wafers were annealed at 1020 degree for 7 seconds in $\mathrm{N}_{2}$ environment using a Rapid Thermal Process (RTP) tool with temperature ramps of about $70 \mathrm{C} / \mathrm{s}$. Obviously, the contaminant distribution at the end of the process flow depends on the contaminant diffusivity, which is quite high in some cases, ${ }^{2}$ so the contaminant diffusion and segregation can be more important than the implantation conditions in determining the contaminant impact on the electrical results.

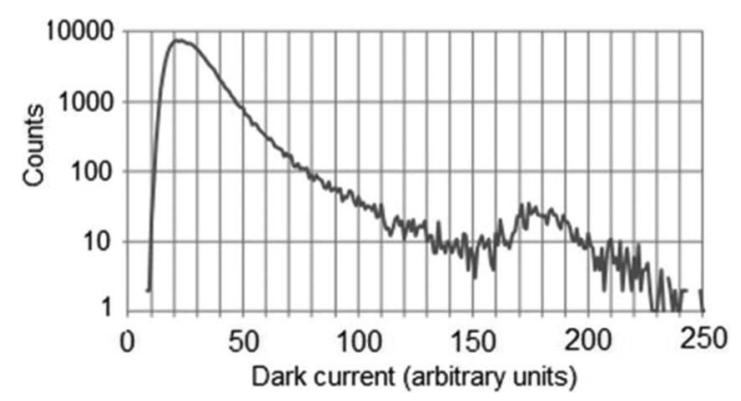




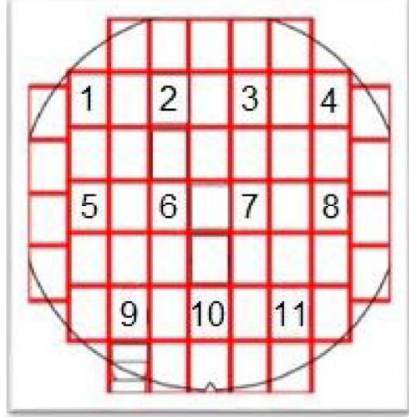

(a)

\begin{tabular}{|c|c|}
\hline Metal & Shot \\
\hline $\mathrm{Cu}$ & 1 \\
\hline $\mathrm{V}$ & 2 \\
\hline $\mathrm{Cr}$ & 3 \\
\hline $\mathrm{Ni}$ & 4 \\
\hline $\mathrm{Fe}$ & 5 \\
\hline $\mathrm{Ti}$ & 6 \\
\hline $\mathrm{Mo}$ & 7 \\
\hline $\mathrm{W}$ & 8 \\
\hline $\mathrm{Al}$ & 9 \\
\hline Baseline & 10 \\
\hline $\mathrm{Zn}$ & 11 \\
\hline
\end{tabular}

(b)

Figure 2. (a) wafer map with shot numbers; (b) link between shot number and metallic element. "Baseline" indicates the un-contaminated sample.

The central implantation DOE conditions (see Table I) were used for the analysis of the dark current as a function of temperature.

Ion implantation was chosen as the contamination method because by this method different dice of the wafer can be contaminated with known doses of different elements. This method has the drawback of the implantation damage, which can evolve into extended crystal defects and impact the dark current, making it difficult to identify the contribution related to the contaminant. However, the doses used in our experiment (see Table I) are lower than the typical threshold doses for defect formation. ${ }^{9,10}$ In addition, previous experiments showed (see

Table I. Implant dose/energy for every metal used in the experiment.

\begin{tabular}{ccc} 
Element & Energy $(\mathrm{keV})$ & Dose $\left(\mathrm{cm}^{-2}\right)$ \\
\hline Molybdenum & 14 & $5 \cdot 10^{8}$ \\
& 14 & $5 \cdot 10^{9}$ \\
& 32 & $2.75 \cdot 10^{9}$ \\
& 60 & $5 \cdot 10^{8}$ \\
& 60 & $5 \cdot 10^{9}$ \\
Tungsten & 10 & $1.2 \cdot 10^{9}$ \\
& 10 & $1.2 \cdot 10^{10}$ \\
& 19 & $6.6 \cdot 10^{9}$ \\
Copper & 40 & $1.2 \cdot 10^{9}$ \\
Nickel & 40 & $1.2 \cdot 10^{10}$ \\
Iron & 25 & $2.75 \cdot 10^{10}$ \\
Chromium & 25 & $3.3 \cdot 10^{10}$ \\
Zinc & 25 & $3.3 \cdot 10^{10}$ \\
Titanium & 23 & $3.3 \cdot 10^{10}$ \\
& 27 & $3.3 \cdot 10^{10}$ \\
& 10 & $10^{11}$ \\
& 10 & $10^{12}$ \\
Aluminum & 20 & $5.5 \cdot 10^{11}$ \\
Vanadium & 80 & $10^{11}$ \\
& 80 & $10^{12}$ \\
& 11 & $10^{11}$ \\
& 11 & $10^{12}$ \\
& 23 & $5.5 \cdot 10^{11}$ \\
& 45 & $10^{11}$ \\
& 45 & $10^{12}$ \\
& & $5.5 \cdot 10^{11}$
\end{tabular}

\section{lon Range $=171 \mathrm{~A}$ Skewness $=0.332$ Straggle $=37 \mathrm{~A} \quad$ Kurtosis $=3.432$}

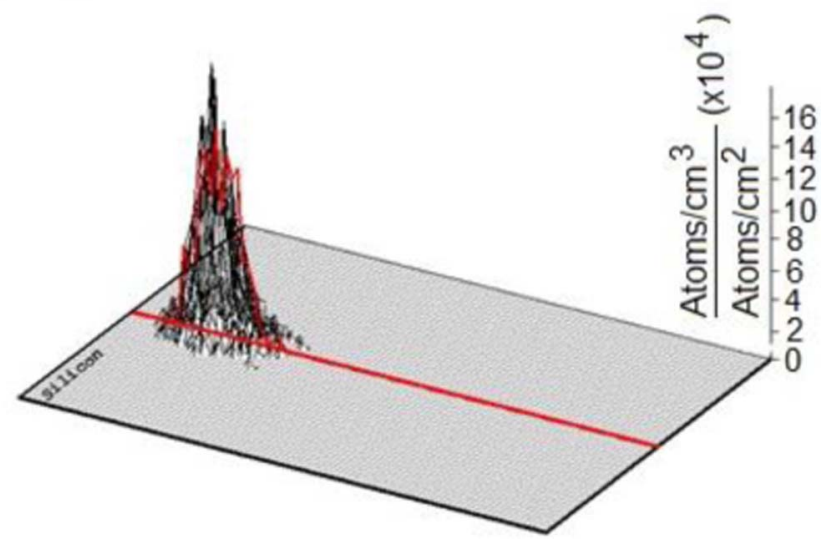

Figure 3. Example of SRIM simulation for $\mathrm{W}$ at $10 \mathrm{keV}$ and different doses as shown on the right. The doping concentration is reported on the $\mathrm{z}$ axis. The red line represents the 1-D concentration in the implantation direction; the black lines represent the 2-D concentration.

for instance ${ }^{11}$ ) that the generation-recombination properties of silicon implanted with low dose metals and the deep levels observed by Deep Level Transient Spectroscopy (DLTS) are specific of the contaminant, irrespective of the implantation lattice damage.

Analysis of dark current versus temperature.-No bias is applied during the charge integration time to the pinned photodiode used in CMOS image sensor (standard 4 transistor cell ${ }^{12}$ ).

The photodiode is reset at the beginning of the integration time. By activating the transfer gate and the reset gate the diode is connected to a high reverse voltage (typically from 2.8 to $3.3 \mathrm{~V}$ ). In this reset phase the $\mathrm{n}^{-}$region of the diode is fully depleted (no electrons remain in the quantum well). During the integration time the transfer gate and the reset gate are turned off, and the quantum well integrates charge (thermally generated or photogenerated), with no applied bias. The electric field in the junction space charge region was calculated by a device modeling program (Sentaurus ${ }^{13}$ by Synopsis). During the integration time, the electric field was found to be in rather low (of the order of $10^{4} \mathrm{~V} / \mathrm{cm}$ ), so the effect of the electric field on carrier generation can be neglected. ${ }^{14}$

The dark current $\mathrm{I}$ has been analyzed as a function of the measurement temperature $\mathrm{T}$ in the range $25^{\circ} \mathrm{C}-90^{\circ} \mathrm{C}$ according to the following equation:

$I=I_{d i f f}+I_{g e n}=A T^{3} \exp \left(-\frac{E_{g}}{k T}\right)+B T^{3 / 2} \exp \left(-\frac{E_{g} / 2+\Delta E}{k T}\right)$

with $\mathrm{I}_{\text {diff }}$ the diffusion current (due to carriers generated in the neutral region of junction), $I_{\text {gen }}$ the generation-recombination current (due to carriers generated in the depleted region of the junction), $E_{g}$ the silicon gap energy, $\Delta E=\left|E_{t}-E_{i}\right|, k$ the Boltzmann constant, $\mathrm{E}_{\mathrm{t}}$ the energy level of generation-recombination (GR) center and $E_{i}$ the intrinsic Fermi level. A, B and $\Delta \mathrm{E}$ are used as fitting parameters. To notice that $A \propto 1 / L_{\text {diff }} \propto \sqrt{\sigma N_{T}}$ and $B \propto 1 / \tau_{0} \propto \sigma N_{T}$, where $\mathrm{L}_{\text {diff }}$ is the carrier diffusion length in the neutral region, $\mathrm{N}_{\mathrm{t}}$ the deep centers concentration, $\tau_{0}$ the minority carrier recombination lifetime and $\sigma$ the carrier capture cross section (with a rough approximation, a single value for minority and majority carriers is assumed). The dark current is obtained as the rate of increase of electron count over time in dark conditions. Such estimation is considered reliable if the count of electrons linearly increases with time. Therefore, the correlation coefficient $\mathrm{R}$ that gives the quality of least square fitting is used as a parameter to identify and discard unreliable data. The following 
procedure was used to select the $\mathrm{I}(\mathrm{T})$ data for the analysis based on the best-fit to Eq. 1:

- First, the dark current distribution was obtained. Dark current data are assumed to be reliable if $\mathrm{R}^{2}>0.9$. At low temperature the current is very low, and therefore this condition is frequently not fulfilled, thus reducing the number of reliable data. For a statistical sample of sufficient reliability $\left(\approx 10^{4}\right.$ data $)$, the current distributions at $60^{\circ} \mathrm{C}$ were studied.

- Junctions with reverse current in the peak of the distribution were chosen for the analysis of the dark current as a function of temperature. In some cases, the reverse current distribution shows more peaks, one common to not contaminated samples and the other typical of contaminant element. In these cases, the latter peak only was chosen for the analysis.

- In some cases the distribution of uncontaminated and contaminated samples are similar to each other. In those cases, in an attempt to catch a signature of contamination, we analyzed diodes belonging to the high current side of the current peak.

- To better estimate $\Delta \mathrm{E}$ it is of key importance to separate the $\mathrm{I}_{\mathrm{gen}}$ component that is dominant at low temperature from the other $\left(\mathrm{I}_{\text {diff }}\right)$ and so the data accuracy in this temperature range is very important for the analysis of the dark current vs. temperature. For this reason, we selected for this analysis only the curves with $\mathrm{R}^{2}>0.9$ both at $25^{\circ} \mathrm{C}$ and $40^{\circ} \mathrm{C}$.

- In order to estimate the diffusion current $\left(\mathrm{I}_{\mathrm{diff}}\right)$, the total current must follow the Equation 1 up to the maximum temperature in the range under study $\left(90^{\circ} \mathrm{C}\right)$, where the diffusion current becomes dominant.

- The presence of a contaminant can increase the A and B value, but cannot reduce them. Hence, if the values of the parameters A and B resulting from the best-fit procedure were definitely below the value of the non-contaminated samples, these values are excluded from statistics.

\section{Results}

Uncontaminated samples.-In the Figure 4 the dark current distribution at $60^{\circ} \mathrm{C}$ is reported for an uncontaminated sample. Fig. 5 shows an example of the fitting procedure of the dark current vs. temperature, and Table II collects the best-fit results. According to the fitting procedure, in not contaminated diodes the generation current is dominated by a level close to midgap $(\Delta \mathrm{E} \approx 0)$. However, in the uncontaminated sample the generation current is a significant component only at low temperatures. This implies a large uncertainty in both $\mathrm{B}$ and $\Delta \mathrm{E}$ parameters.

Molybdenum.-In the literature it is well known that Mo is a slow diffuser. ${ }^{2}$ Thus, even a small amount of this element per unit area results in a significant concentration in the device region. For the

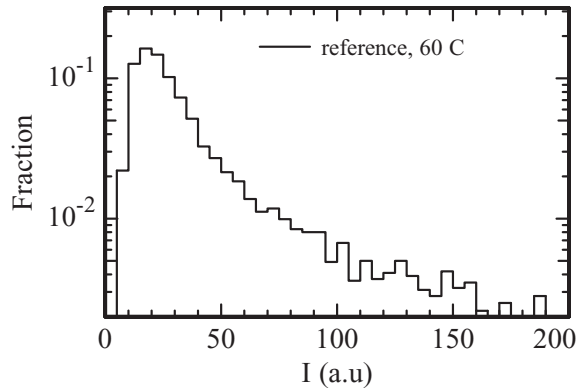

Figure 4. Dark current distribution at $60^{\circ} \mathrm{C}$ for uncontaminated samples (reference distribution)

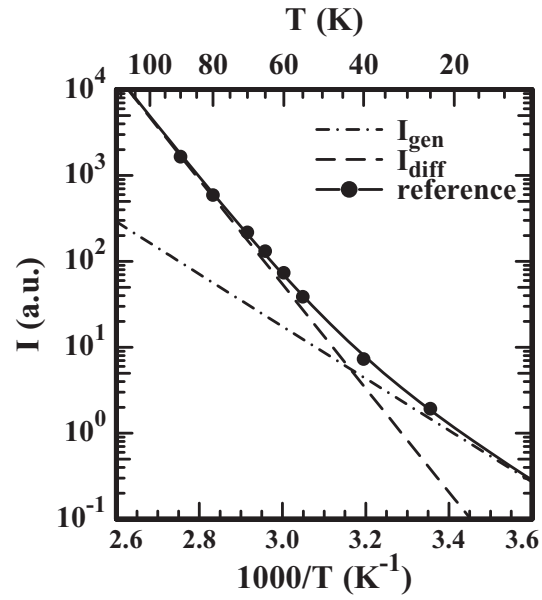

Figure 5. Arrhenius plot of the dark current of a reference uncontaminated sample.

same reason, typical techniques such as back side gettering or intrinsic gettering are not effective. In addition, Mo is known to have a deep level located at $\mathrm{E}_{\mathrm{v}}+0.3 \mathrm{eV},{ }^{15}$ so it is expected to be responsible for dark current excess. Figure 6 reports the dark current distribution at $60^{\circ} \mathrm{C}$ for samples contaminated with Mo. In Mo-contaminated samples, the dark current distribution peaks at a higher current and shows a larger spread than the intrinsic distribution. According to the dark current analysis vs. temperature (see Fig 7 and Table II), $\Delta \mathrm{E}=0.24$ $\pm 0.004 \mathrm{eV}$, in reasonable agreement with the value expected from the literature energy level, i.e. $\Delta \mathrm{E}=0.26 \mathrm{eV}$.

Fig. 7 shows that in Mo-contaminated structures the reverse current is dominated by the generation current. For this reason, the diffusion current obtained by the best fit procedure is affected by large uncertainty.

Table II. Best fit parameters for reference and contaminated diodes. $(0,+)$ indicates a donor level, $(0,-)$ indicates an acceptor level and $(+,++)$ indicates a double donor level.

Best fit results

\begin{tabular}{|c|c|c|c|c|}
\hline \multirow[b]{2}{*}{ Contaminant } & & & & \multirow[b]{2}{*}{$\Delta \mathrm{E}(\mathrm{eV})$ (literature data) } \\
\hline & $\Delta \mathrm{E}(\mathrm{eV})$ & $\mathrm{I}_{\text {diff }}(300 \mathrm{~K})$ (a.u.) & $\mathrm{I}_{\text {gen }}(300 \mathrm{~K})($ a.u. $)$ & \\
\hline No (reference samples) & $\approx 0$ & $0.36 \pm 0.11$ & $\approx 2$ & - \\
\hline Mo & $0.24 \pm 0.004$ & $\approx 0.10$ & $4.1 \pm 0.9$ & $0.26^{15}$ \\
\hline W & $0.19 \pm 0.01$ & $1.8 \pm 0.4$ & $26 \pm 5$ & $0.16(0,+), 0.33(0,-)^{17}$ \\
\hline $\mathrm{Ni}$ & $0.10 \pm 0.04$ & $0.92 \pm 0.5$ & $9.7 \pm 3.3$ & $0.17^{2} 0.05^{29}$ \\
\hline $\mathrm{Fe}$ & $0.10 \pm 0.02$ & $0.25 \pm 0.17$ & $8.8 \pm 1.8$ & 0.13 (effective value) $)^{38}$ \\
\hline $\mathrm{Cr}$ & $\approx 0$ & $0.48 \pm 0.20$ & $13 \pm 4$ & $0.33^{44}$ \\
\hline $\mathrm{V}$ & $0.13 \pm 0.03$ & $0.42 \pm 0.16$ & $8.3 \pm 2.3$ & $0.12(0,+), 0.19(+,++)^{47} 0.11(0,+), 0.25(+,++)^{2}$ \\
\hline $\mathrm{Al}$ & $\approx 0$ & $0.61 \pm 0.30$ & $10 \pm 5$ & Shallow acceptor level ${ }^{50}$ \\
\hline
\end{tabular}




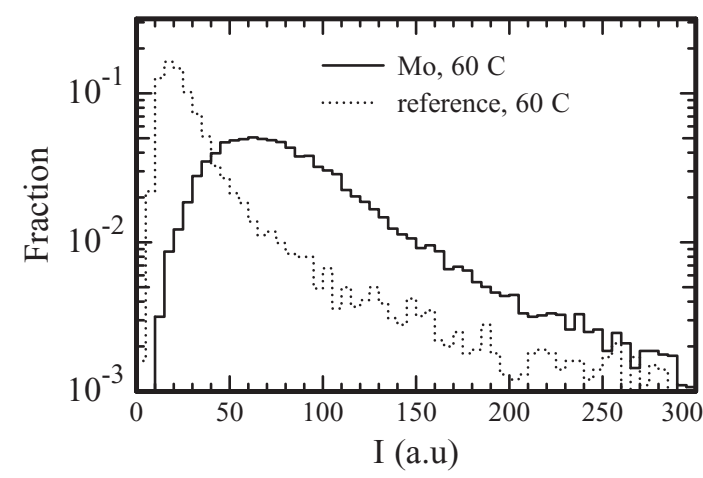

Figure 6. Dark current distribution at $60^{\circ} \mathrm{C}$ for samples contaminated with Mo.

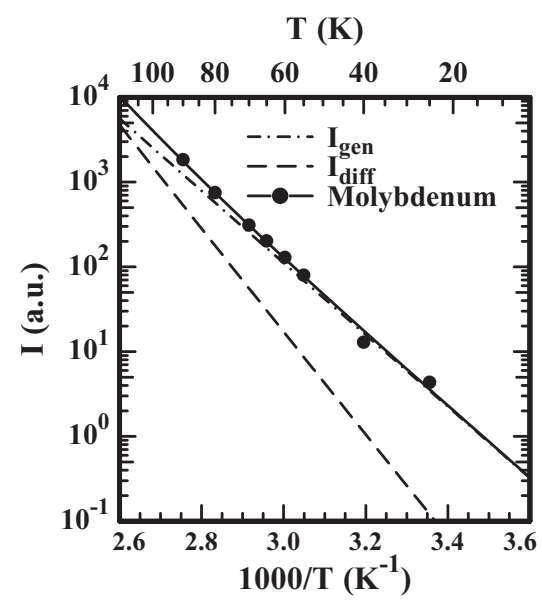

Figure 7. Arrhenius plot of the dark current of a sample contaminated with Mo.

A further analysis was carried out by studying the number of hot pixels (i.e. the number of diodes with leakage current larger than the reference value) as a function of the Mo dose and energy. Fig. 8 shows the box plots of the number of hot pixels per die in wafers with different Mo implantation conditions. The number of hot pixels increases monotonically with the Mo dose up to $5 \cdot 10^{9} \mathrm{~cm}^{-2}$. The implantation energy shows no relevant effect.

Tungsten.-W is reported to have even slower diffusivity than Mo. ${ }^{2}$ Indeed, proximity gettering proved to be less effective for $\mathrm{W}$ than for Mo. ${ }^{16}$ Figure 9 reports the dark current distribution at $60^{\circ} \mathrm{C}$ for samples contaminated with $\mathrm{W}$. The current distribution shows a huge spread, extending to the high current range by more than a factor of 10 with respect to the un-contaminated sample.

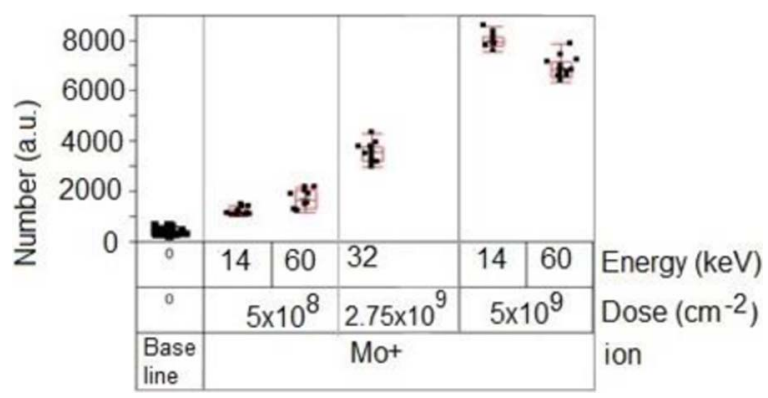

Figure 8. Number of hot pixels versus Mo implantation energy and dose. "Baseline" indicates the uncontaminated sample.

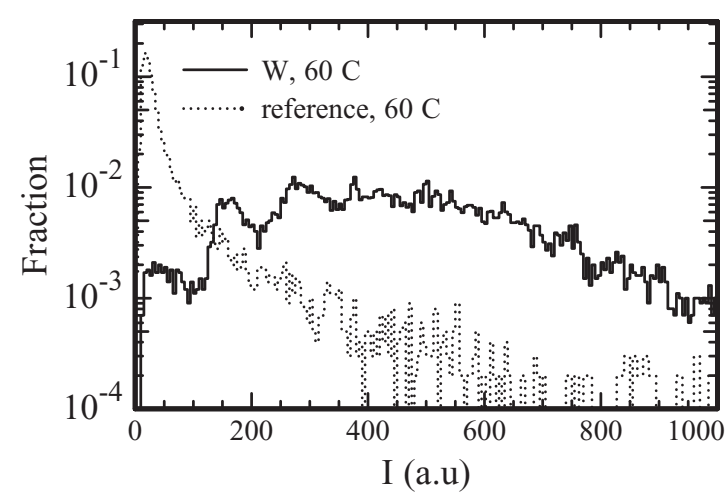

Figure 9. Dark current distribution at $60^{\circ} \mathrm{C}$ for samples contaminated with W.

$\mathrm{W}$ is reported to be responsible for two deep levels, ${ }^{17}$ located respectively at $\mathrm{Ev}+0.4 \mathrm{eV}$ and at $\mathrm{Ec}-0.22 \mathrm{eV}$, so it is not surprising that $\mathrm{W}$ contamination is very effective in increasing the dark current. The level located closest to midgap, i.e. at $\mathrm{E}_{\mathrm{v}}+0.4 \mathrm{eV}$, is expected to be dominant for carrier generation, and so for dark current excess. However, the dark current analysis (see Fig. 10 and Table II) yields $\Delta \mathrm{E}=0.19 \pm 0.01 \mathrm{eV}$. This finding is compatible with a level located at $\mathrm{E}_{\mathrm{v}}+0.36 \mathrm{eV}$, i.e. somewhat lower than the finding in Ref. 17.

In a previous experiment, ${ }^{16}$ we intentionally contaminated p-type wafers with a $\mathrm{W}$-contaminated solution. In that experiment the $\mathrm{W}$ level located at $\mathrm{E}_{\mathrm{v}}+0.4 \mathrm{eV}$ was confirmed, and no other level acting a hole trap was found. However, more $\mathrm{W}$-related hole traps are reported e.g. in Ref. 18, suggesting that the W-related traps may depend on the specific process flow used to prepare the samples. The results in Ref. 17 were obtained in wafers treated with a very short process flow, including one thermal treatment only, whereas the wafers used for the dark current analysis followed the whole device process. Therefore, another experiment was carried out to investigate whether the W level can be affected by some process steps, specifically by Reactive Ion Etching (RIE) processes. ${ }^{19}$ p-Type wafers were analyzed by Deep Level Transient Spectroscopy (DLTS) after RIE-treatment and compared with p-type wafers without an RIE-treatment. A DLS83 instrument by Semilab was used for that experiment. Samples without RIE-treatment showed one peak only, i.e. the peak located at $E_{v}+$ $0.4 \mathrm{eV}$ (named $\mathrm{H}_{1, \mathrm{~W}}$ ) previously observed in Ref. 16 and reported in Ref. 17. The samples after RIE-treatment showed also this peak but in addition they show another peak located at $\mathrm{E}_{\mathrm{v}}+(0.34-0.36) \mathrm{eV}$ (named $\mathrm{H}_{2, \mathrm{~W}}$ ), not far from one of the levels reported in Ref. 18, i.e. $\mathrm{E}_{\mathrm{v}}+0.33 \mathrm{eV}$, and rather close to the estimate obtained from the dark

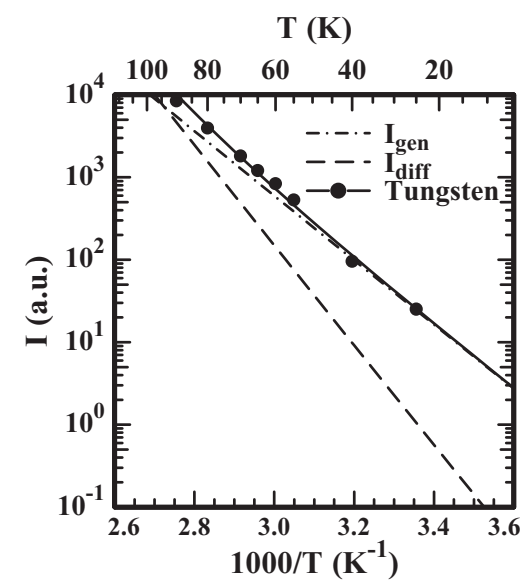

Figure 10. Arrhenius plot of the dark current of a sample contaminated with W. 


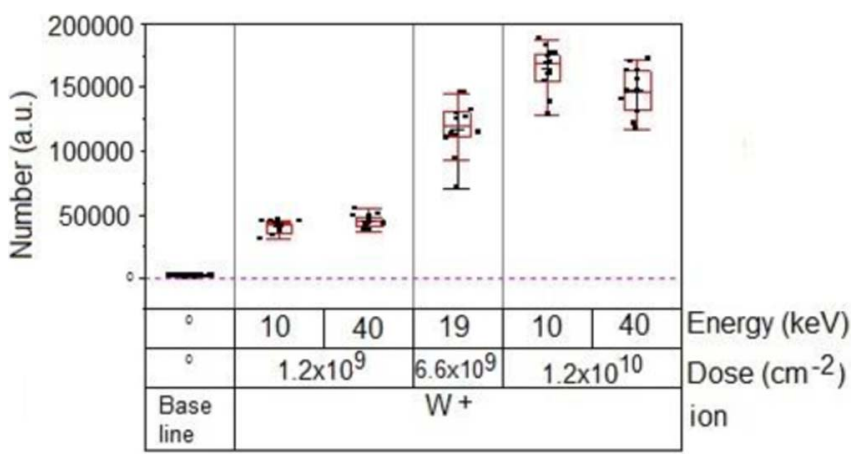

Figure 11. Number of hot pixels in a.u. versus $\mathrm{W}$ implantation energy and dose.

current analysis. Our experiments suggested that the level located at $\mathrm{E}_{\mathrm{v}}+(0.34-0.36) \mathrm{eV}$ may be due to a complex with some element introduced by the dry etching process, e.g. with fluorine or hydrogen. These experiments cannot simulate a whole process flow, however these results show that W-related levels with lower energy than the energy of peak $\mathrm{H}_{1}$,w can be formed even by a single dry etching step. According to the data in Ref. 16, the hole capture cross section of $\mathrm{H}_{2, \mathrm{~W}}$ $\sigma_{\mathrm{h} 2, \mathrm{~W}}$ is about one order of magnitude larger than the cross section of $\mathrm{H}_{1, \mathrm{~W}} \sigma_{\mathrm{h} 1, \mathrm{~W}}\left(\sigma_{\mathrm{h} 1, \mathrm{~W}} \approx 2 \cdot 10^{-15} \mathrm{~cm}^{2}, \sigma_{\mathrm{h} 2, \mathrm{~W}} \approx 10^{-14} \mathrm{~cm}^{2}\right)$. If the concentrations of the two levels are comparable, the contribution to carrier generation should be similar for the two levels. As $\mathrm{H}_{2, \mathrm{~W}}$ is found to be dominant over $\mathrm{H}_{1, \mathrm{w}}$ in carrier generation, we conclude that at the end of the full device process the $\mathrm{H}_{2, \mathrm{~W}}$ concentration is higher than the $\mathrm{H}_{1, \mathrm{w}}$ concentration.

In addition, Fig. 10 and Table II show that W contamination increases not only the generation current, but also the diffusion current. This contribution is due to carrier generation in the neutral region of the junction. Thus, $\mathrm{W}$ is also effective for carrier generation in the neutral region. This finding is in agreement with generation lifetime measurements obtained by the Zerbst technique ${ }^{20}$ in W-contaminated capacitors. ${ }^{21}$

Finally, the Figure 11 summarize the results of $\mathrm{W}$ experiment reporting the number of hot pixels (see Mo section for definition) versus the energy and dose of implantation. For the same energy a dose increase results in a higher number of hot pixels (a $3 \mathrm{x}$ factor for the range explored) while at the same dose an energy increase doesn't change significantly the number of hot pixels.

Copper.- $\mathrm{Cu}$ is the fastest diffuser in silicon, ${ }^{2,22}$ with a significant diffusivity even at room temperature. For this reason, $\mathrm{Cu}$ is unlikely to remains in solution in silicon after a thermal budget in a furnace or RTP, and usually segregates completely at the wafer surface or at getter sites. An experiment ${ }^{23}$ was set up to investigate the $\mathrm{Cu}$ recombination activity and to discriminate between bulk and surface recombination in $\mathrm{Cu}$-contaminated silicon. It was shown that the carrier recombination in the $\mathrm{Cu}$-contaminated region was essentially due to surface recombination. No $\mathrm{Cu}$-related recombination could be detected in the silicon volume. $\mathrm{Cu}$ precipitates at the wafer surface were actually observed by TEM (Transmission Electron Microscope) both in cross section and in plan view by using a LEO 922 TEM by Zeiss. In addition, $\mathrm{Cu}$ gettering by bulk defects and by the $\mathrm{p}^{+}$region of the $\mathrm{p} / \mathrm{p}^{+}$epitaxial substrate has long been known (see for instance ${ }^{24-26}$ ). Therefore, $\mathrm{Cu}$ contamination is not expected to have a relevant impact on the dark current.

On the contrary, the dark current distribution of $\mathrm{Cu}$-contaminated diodes (Fig. 12) peaked at a higher current and showed larger dispersion with respect to the un-contaminated sample. Fig. 13 reports the Arrhenius plot of the dark current in a $\mathrm{Cu}$-contaminated diode, as well as the best-fit curve and the diffusion and the generation contributions. The average results of the fitting procedure are reported in Table II. Both the diffusion and the generation current are higher than the corresponding contributions in reference diodes. The generation current

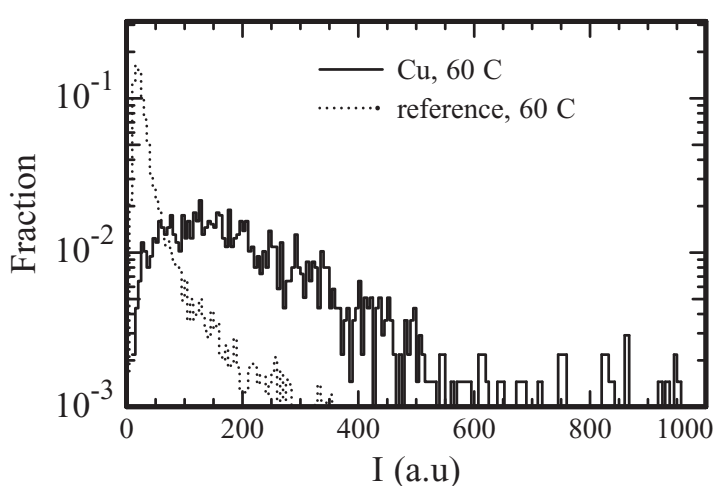

Figure 12. Dark current distribution at $60^{\circ} \mathrm{C}$ for samples contaminated with $\mathrm{Cu}$.

appears to be dominated by a midgap level $\left(\Delta \mathrm{E}=(1 \pm 3) \cdot 10^{-2} \mathrm{eV}\right)$, which is not reported among the levels related to $\mathrm{Cu}{ }^{2,22,27}$

The observed effects can be related to the formation of $\mathrm{Cu}$ complexes or to $\mathrm{Cu}$ decoration of crystal defects, rather than single $\mathrm{Cu}$ atoms in solution in the silicon lattice. For instance bulk defects decorated by $\mathrm{Cu}$ can increase significantly their electrical activity, and hence the diffusion current. However, it is worth noting that the generation current increase does not consist in a "soft" contribution, as it happens when metal precipitates are large enough to shrink the space charge region and induce a local band-to-band tunnel effect. ${ }^{28}$ Indeed, in that case the reverse current is expected to deviate from Eq. 1 and to be weakly dependent on temperature, but this is not the case, as shown in Fig. 13. Therefore, the observed generation current increase can only be due to $\mathrm{Cu}$ complexes or small precipitates, which do not significantly alter the electric field in the junction space charge region but act as a continuum of energetic levels ${ }^{22}$ with the dominant levels the ones closest to midgap.

Nickel.-The Ni diffusivity is very high even at temperatures close to room temperature, when its solid solubility is close to $0 .^{2}$ For this reason, Ni usually segregates at the wafer surface or at crystal defects, specifically in furnace treatments.

The dark current distribution for samples contaminated with $\mathrm{Ni}$ (Fig. 14) is rather similar to the distribution of uncontaminated ones. A limited shift to high currents and a modest increase of the high current tail can be noticed only. The analysis of the reverse current shows that both the diffusion and generation currents are higher with respect to the uncontaminated samples (see Fig. 15 and Table II). Ni like $\mathrm{Cu}$ rarely remains in solid solution while very often precipitates

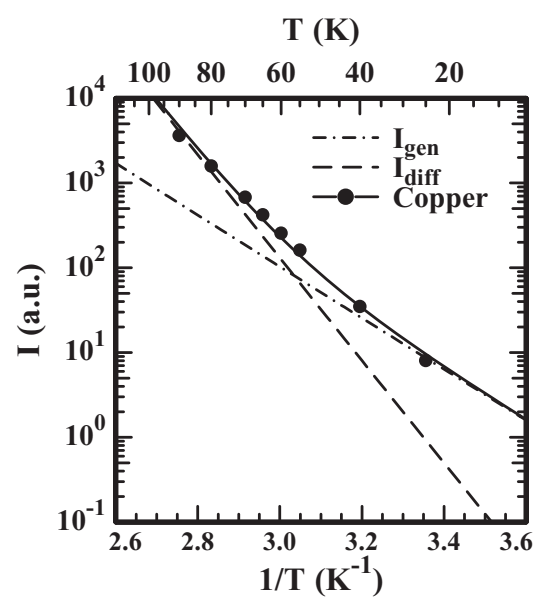

Figure 13. Arrhenius plot of the dark current of a sample contaminated with $\mathrm{Cu}$ 


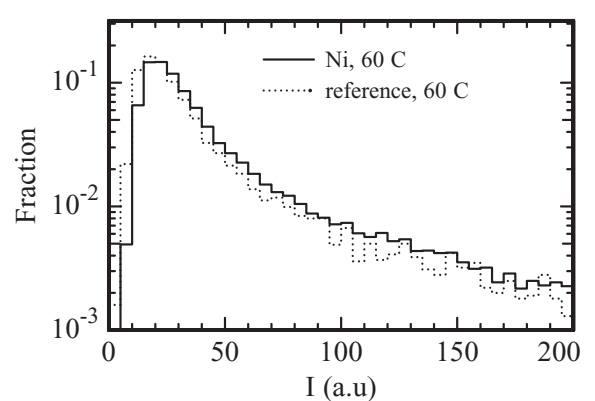

Figure 14. Dark current distribution at $60^{\circ} \mathrm{C}$ for samples contaminated with $\mathrm{Ni}$.

on pre-existing nuclei or by creating new precipitating nuclei. ${ }^{22,29}$ This can explain the large spread of fit results in $\mathrm{Ni}$-contaminated junctions, as well as the dispersion of literature data. The energy level obtained using the best-fit of dark current versus the temperature is within the interval of literature data $(\Delta \mathrm{E}=0.1 \pm 0.04$, to be compared with Refs. 2 and 29).

The same experiment as just discussed for $\mathrm{Cu}$ was also repeated for $\mathrm{Ni},{ }^{23}$ to investigate the $\mathrm{Ni}$ recombination activity and to discriminate between bulk and surface recombination in $\mathrm{Ni}$-contaminated silicon. The results were quite similar to those obtained for $\mathrm{Cu}$. Ni also showed no recombination activity in the silicon volume. The results indicated that the carrier recombination rate in the $\mathrm{Ni}$-contaminated region was essentially controlled by surface recombination and Ni-precipitates at the wafer surface could also be observed by TEM.

$\mathrm{Ni}$ is also easily gettered both by oxygen-related defects and by boron high doping (see for instance ${ }^{30,31}$ ). A specific experiment was carried out to test the gettering ability of bulk defect and of high boron concentration regions. ${ }^{32}$ According to our findings the generation lifetime is heavily degraded by Ni-contamination in the absence of gettering sites. However, both gettering by bulk defects and gettering by the $\mathrm{p}^{+}$region of the epitaxial substrate proved to be very effective in preventing the Ni-related generation lifetime degradation. Best performances were obtained in $\mathrm{p} / \mathrm{p}^{+}$epitaxial substrates. According to these results, $\mathrm{Ni}$ gettering is expected in the image sensor process, thus explaining the limited impact of $\mathrm{Ni}$ contamination on the dark current in a large fraction of the diode population.

A NiSi layer self-aligned to the source and drain junctions of transistors is frequently used in advanced devices. ${ }^{33-35} \mathrm{Ni}$ can diffuse in the junction space charge region, and for this reason the impact of nickel contamination on junction leakage was studied in the past. It was shown that Ni diffusion increases the junction reverse current. ${ }^{34}$

T (K)

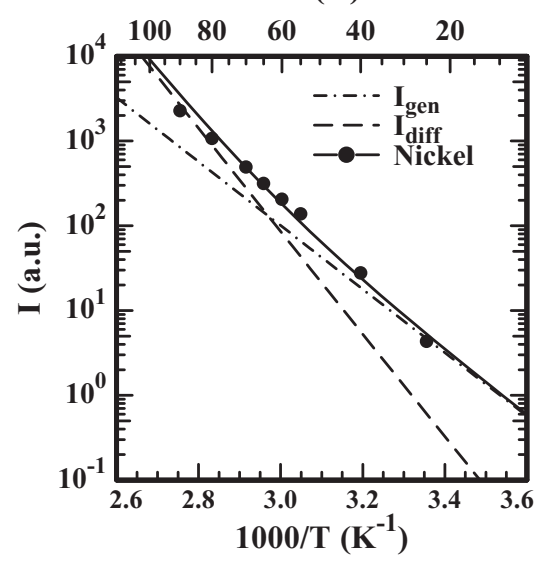

Figure 15. Arrhenius plot of the dark current of a sample contaminated with Ni.

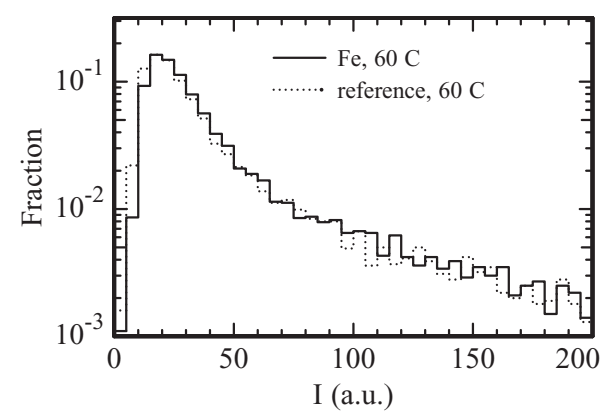

Figure 16. Dark current distribution at $60^{\circ} \mathrm{C}$ for samples contaminated with $\mathrm{Fe}$.

Similarly to what observed in this work, the reverse current of Nicontaminated junctions was found to be described by the SRH model, though in that case the dominant level was found to be close to midgap. Ni-related generation-recombination centers were ascribed to Ni clusters. On the other hand, $\mathrm{Ni}$ is found to be easily gettered by phosphorus heavy doping. ${ }^{36}$

Iron.-Fe is a very well-known fast diffuser, ${ }^{2}$ though not as fast as $\mathrm{Cu}$ and $\mathrm{Ni}$. In addition, $\mathrm{Fe}$ is known to form a pair with boron, which is the equilibrium state in p-type silicon at room temperature. Both interstitial $\mathrm{Fe}\left(\mathrm{Fe}_{\mathrm{i}}\right)$ and the $\mathrm{FeB}$ pair are effective recombination centers. ${ }^{37}$ Indeed, it was shown that $10^{11} \mathrm{~cm}^{-2} \mathrm{Fe}$ dose is enough to degrade the carrier lifetime by more than one order of magnitude, so $\mathrm{Fe}$ contamination is potentially harmful for devices requiring strict control of the carrier lifetime. The dark current distribution for our samples contaminated with $\mathrm{Fe}$ is very similar to the distribution of uncontaminated samples (see Fig. 16).

However, the dark current analysis shows that the Fe contamination increases the generation current, leaving the diffusion current unchanged (see Fig. 17 and Table II). The energy level obtained using the best-fit of dark current versus the temperature is in rather good agreement with the literature data. As $\mathrm{p}^{+} / \mathrm{n}$ diodes are being studied, the depletion region extends on the n-type side, where $\mathrm{Fe}_{\mathrm{i}}$ is expected, not $\mathrm{FeB}$ pairs. Actually, $\mathrm{Fe}_{\mathrm{i}}$ has a donor level with effective energy $\mathrm{E}_{\mathrm{v}}+0.43 \mathrm{eV}^{38}$ To avoid confusion, we recall that the energy level of $\mathrm{Fe}_{\mathrm{i}}$ is located at $\mathrm{E}_{\mathrm{v}}+0.37 \mathrm{eV}$, and the hole capture cross section is temperature activated with $0.048 \mathrm{eV}$. The temperature dependence of the capture cross section affects both DLTS and reverse current measurements, resulting in an apparent energy $\mathrm{E}_{\mathrm{v}}+0.43 \mathrm{eV}$. Hence, the expected value of $\Delta \mathrm{E}$ is $0.13 \mathrm{eV}$, and we obtain $\Delta \mathrm{E}=0.10 \pm$ 0.02 . However, even if Fe strongly enhances carrier recombination - 


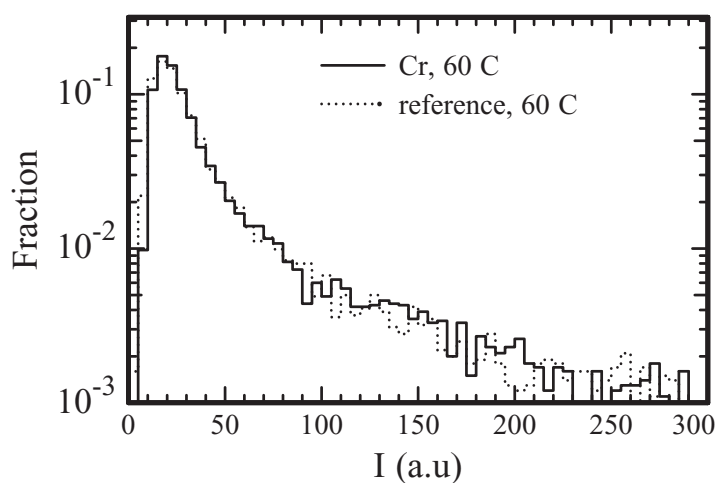

Figure 18. Dark current distribution at $60^{\circ} \mathrm{C}$ for samples contaminated with $\mathrm{Cr}$.

particularly, in p-type silicon - the reverse current distribution is not affected by Fe under present contamination conditions.

To explain this result, it is worth recalling that $\mathrm{Fe}$ can be easily gettered due to its high mobility and to the formation of FeB pairs. Boron doping $^{23}$ and phosphorus doping ${ }^{39}$ were shown to provide effective gettering. In addition, it was shown that a furnace treatment with a slow cool down rate improves gettering efficiency of fast diffusers such as Fe. ${ }^{40}$ Some of these segregation gettering mechanisms ${ }^{41,42}$ are active in the process flow for the fabrication of the image sensors, for instance gettering by boron doping in the $\mathrm{p}^{+}$region of the epitaxial substrate. Furnace treatments along the process flow may improve the effectiveness of this gettering mechanism. These effects explain why $\mathrm{Fe}$ contamination is not responsible for a relevant dark current increase, in spite of its efficiency as a recombination center. Finally, by comparing the results of $\mathrm{Fe}, \mathrm{Ni}$ and $\mathrm{Cu}$ contaminated samples, we conclude that in our process flow gettering has been more effective for $\mathrm{Fe}$ and $\mathrm{Ni}$ than for $\mathrm{Cu}$.

Chromium.-Cr is a rather fast diffuser, ${ }^{2}$ though slower than Fe. During a whole device process, $\mathrm{Cr}$ is expected to diffuse through more than $100 \mu \mathrm{m}$, so it can easily reach gettering sites. Cr pairs with boron, ${ }^{43}$ so both bulk defects and the high boron concentration in $\mathrm{p}^{+}$ region of the $\mathrm{p} / \mathrm{p}^{+}$epitaxial wafer can act as the getter sites. The Fig. 18 show the dark current distribution for dies contaminated with $\mathrm{Cr}$. This distribution is very similar to the reference distribution.

The results of the analysis of the dark current vs. temperature are reported in Fig. 19 and in Table II. The dominant energy level is close to midgap, i.e. $\Delta \mathrm{E} \approx 0$, very similar to the datum of uncontaminated samples. Even though several junctions with current in the high cur-

T (K)

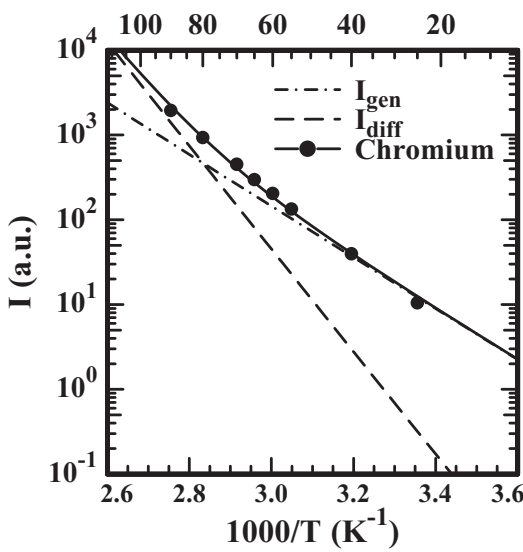

Figure 19. Arrhenius plot of the dark current of a sample contaminated with Cr.

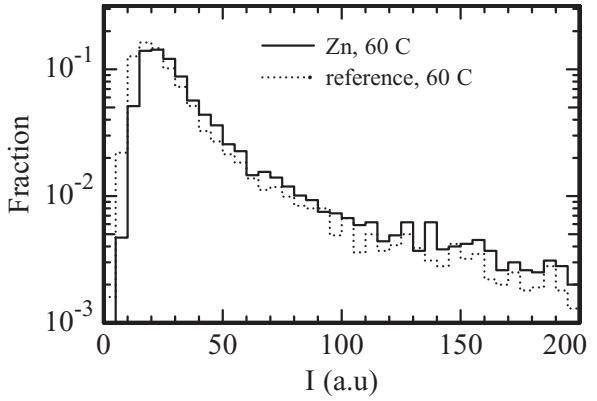

Figure 20. Dark current distribution at $40^{\circ} \mathrm{C}$ for samples contaminated with $\mathrm{Zn}$.

rent side of the distribution peak were analyzed, the trap level has not been observed in our experiments as reported in Reference 44 concerning the interstitial $\mathrm{Cr}$. Cr-contaminated p-type wafers were analyzed by carrier lifetime measurements and by DLTS in a previous experiment. ${ }^{45}$ In this work it has been highlighted that $\mathrm{Cr}$ has limited efficiency as a recombination center, and in addition it is easily gettered by bulk defects during the device processes. It can be the reason why our analyses do not show significant impact of $\mathrm{Cr}$ contamination on the dark current.

Zinc.-The dark current distribution for $\mathrm{Zn}$ contamination (Fig. 20) is rather similar to the one of un-contaminated samples, with a limited shift to high currents and a modest increase of the high current tail only. However, the accurate analysis of the dark current as a function of temperature shows some impact of $\mathrm{Zn}$ contamination. Fig. 21 shows the Arrhenius plot of the dark current in a $\mathrm{Zn}$-contaminated diode, and Table II reports the average results of the fitting procedure. The activation energy obtained in our experiment is well aligned with the expected trap level data according to Ref. $2(\Delta \mathrm{E} \approx 0)$. In addition, the reverse current increment is due to generation current only.

$\mathrm{Zn}$ is reported $\mathrm{d}^{2}$ to completely evaporate during thermal treatments, unless a closed ampoule is used for $\mathrm{Zn}$ diffusion. $\mathrm{Zn}$ evaporation probably took place in the image sensor process too, however our analysis indicates that a fraction of the implanted dose remains in the solid solution in the silicon volume. As a midgap level, $\mathrm{Zn}$ is expected to be a very effective generation center, so a very small amount can be responsible for the observed increment of the generation current.

Titanium.-The samples contaminated with Ti (Fig. 22) show a dark current distribution peak shifted toward higher current values and a larger dispersion with respect to the uncontaminated reference. The 


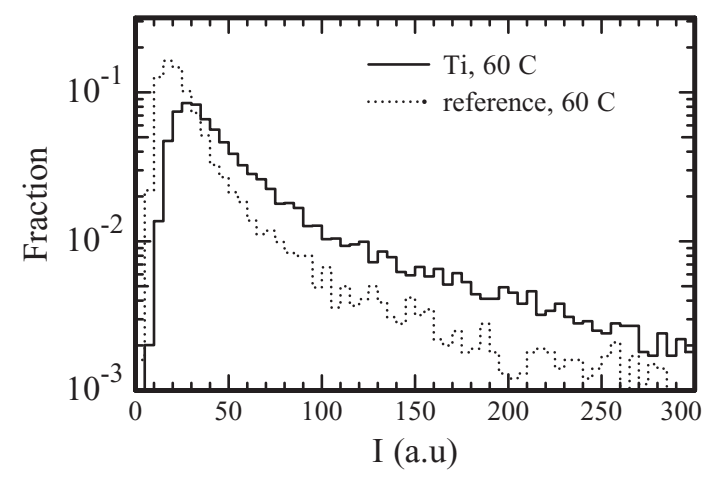

Figure 22. Dark current distribution at $60^{\circ} \mathrm{C}$ for samples contaminated with Ti.

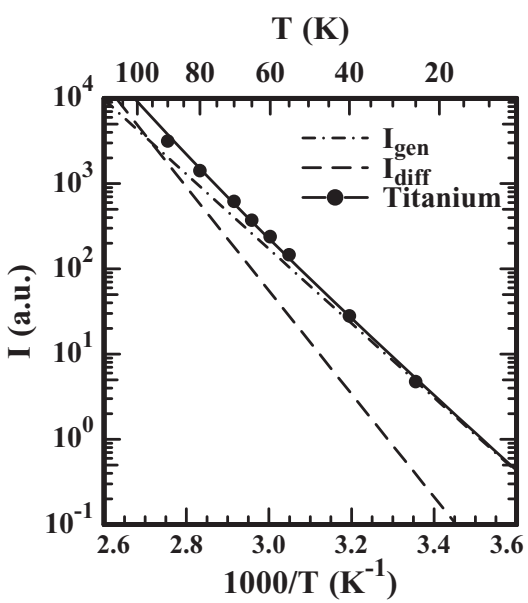

Figure 23. Arrhenius plot of the dark current of a sample contaminated with Ti.

best fit results reported in Fig. 23 and Table II show that the generation current for $\mathrm{Ti}$ samples is increased with respect to uncontaminated ones while the diffusion current remains unchanged.

According to the dark current analysis, $\Delta \mathrm{E}=0.25 \pm 0.01 \mathrm{eV}$. This datum is well aligned with what expected from the literature. ${ }^{46}$ Indeed, Ti has three deep levels in silicon, a double donor at $\mathrm{E}_{\mathrm{v}}+$ $0.30 \mathrm{eV}$, a single donor at $\mathrm{E}_{\mathrm{c}}-0.27 \mathrm{eV}$ and an acceptor level at $\mathrm{E}_{\mathrm{c}}$ $0.08 \mathrm{eV}$. The double donor level and the donor level are expected to dominate the generation current, and the expected $\Delta \mathrm{E}$ is $0.26-0.29$ $\mathrm{eV}$, in reasonable agreement with the experimental datum. Concerning the diffusivity we recall that $\mathrm{Ti}$ is comparable to $\mathrm{Mo}^{2}$

A further analysis was carried out to study the number of hot pixels as a function of the Ti dose and energy. The result (Fig. 24) shows a

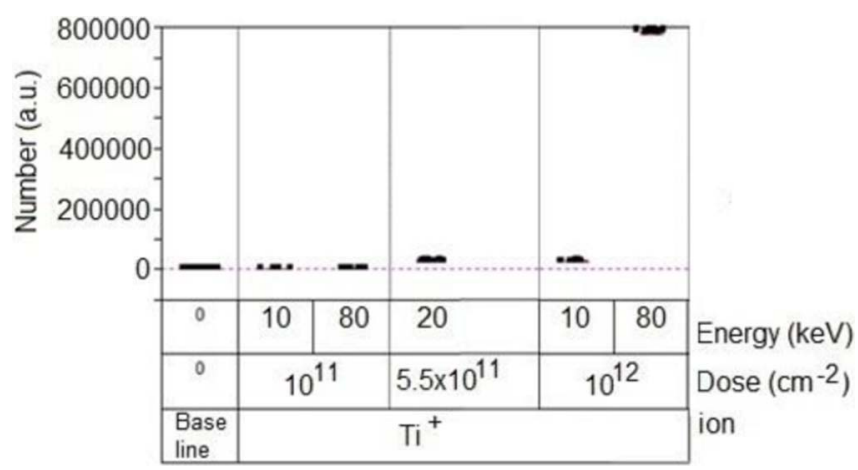

Figure 24. Number of hot pixels in a.u. versus Ti implantation energy and dose.

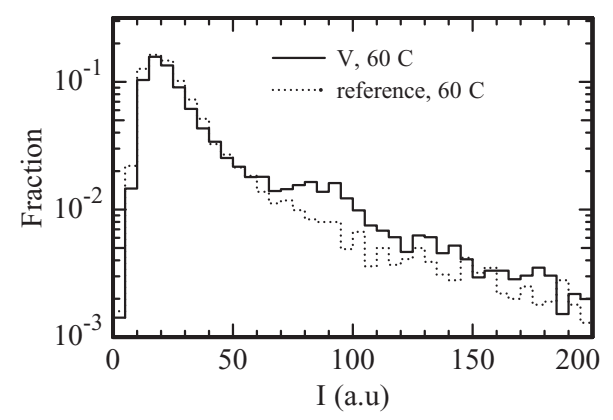

Figure 25. Dark current distribution at $60^{\circ} \mathrm{C}$ for samples contaminated with V.

threshold behavior as a function of dose and energy. For example by increasing the energy from $10 \mathrm{KeV}$ to $80 \mathrm{KeV}$ with a dose of $10^{11}$ $\mathrm{cm}^{-2}$ the number of hot pixels increases by a factor of $\sim 2$ while for a dose of $10^{12} \mathrm{~cm}^{-2}$ the enhancement factor related to implantation energy increases to about a factor of 31 . We have no explanation for the effect of implantation energy, which is observed for Ti only.

Vanadium.- $-\mathrm{V}$ is reported to be a rather slow diffuser, ${ }^{2}$ though less slow with respect to $\mathrm{Ti}$ and Mo. In addition $\mathrm{V}$ too is responsible for deep levels (see for instance ${ }^{47}$ ), so it is expected to have similar impact on the dark current like Mo and Ti. Figure 25 reports the dark current distribution for samples contaminated with $\mathrm{V}$. The main peak of the distribution is the same as in the reference distribution, but in addition a secondary peak characteristic of $\mathrm{V}$ contamination is observed at higher current. As previously mentioned, structures with dark current in this part of the distribution were chosen for the analysis of dark current vs. temperature (see the results Fig 26 and Table II). This analysis shows that in V-contaminated diodes the dark current increases essentially because of the generation current, while the diffusion current is unchanged.

The most commonly reported $\mathrm{V}$ levels are located at $\mathrm{E}_{\mathrm{v}}+0.31$ $\mathrm{eV}, \mathrm{E}_{\mathrm{c}}-0.45 \mathrm{eV}$ and $\mathrm{E}_{\mathrm{c}}-0.18 \mathrm{eV}$. According to the SRH model, the level located closest to midgap is expected to be dominant for carrier generation. Consistently, in our experiment we obtained $\Delta \mathrm{E}=0.13$ $\pm 0.03 \mathrm{eV}$, compatible with the level located at $\mathrm{E}_{\mathrm{c}}-0.45 \mathrm{eV}$.

Finally, Fig. 27 reports the boxplot of the hot pixels per die as a function of the $\mathrm{V}$ dose and implantation energy.

Aluminum.- $\mathrm{Al}$ is a common contaminant in silicon technology, ${ }^{48}$ however it is considered to be less critical than transition metals for devices. ${ }^{49}$ For the $\mathrm{Al}$ the dark current distribution is very similar to

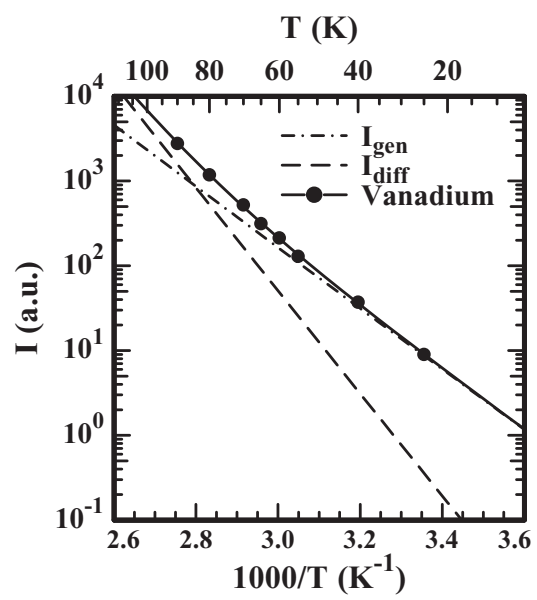

Figure 26. Arrhenius plot of the dark current of a sample contaminated with $\mathrm{V}$. 


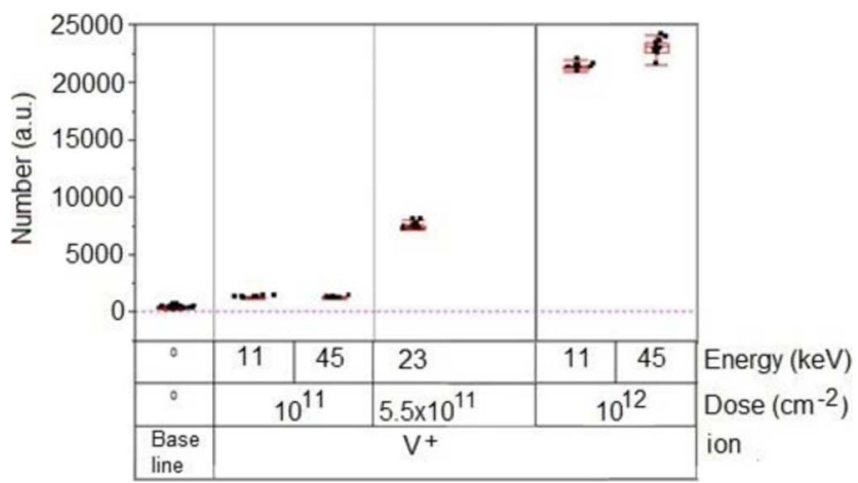

Figure 27. Number of hot pixels in a.u. versus V implantation energy and dose.

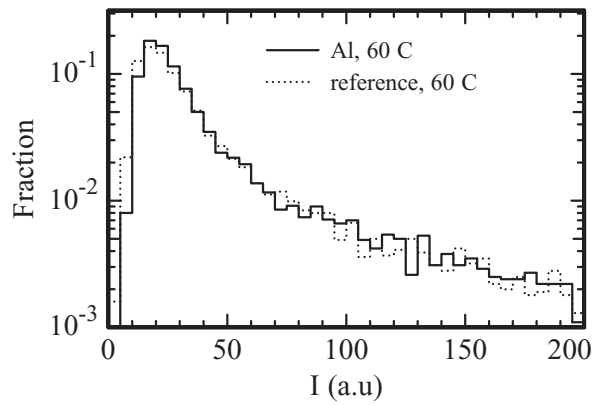

Figure 28. Dark current distribution at $40^{\circ} \mathrm{C}$ for samples contaminated with Al.

the distribution of uncontaminated samples (Fig. 28). Fig. 29 shows the Arrhenius plot of the dark current in an Al-contaminated diode, and Table II reports the best-fit results. The best-fit procedure yields $\Delta \mathrm{E} \approx 0$, the same as in reference samples. Due to its position in the periodic Table, $\mathrm{Al}$ is a shallow acceptor, commonly used for silicon doping when deep-diffused p-type regions are required. ${ }^{50}$ As a shallow acceptor, $\mathrm{Al}$ is not effective for carrier generation and hence no significant impact of $\mathrm{Al}$ on image sensor performances is expected.

\section{Conclusions}

Table III collects the results of the best-fit procedure of dark current data according to Eq. 1, and compares these results with literature data of the energy levels related to the various contaminants.

In many cases (Mo, W, Fe, Ti and $\mathrm{V}$ contamination) the generation current is dominant over the diffusion current in the whole temperature interval. In those cases, the best-fit value of the diffusion current must

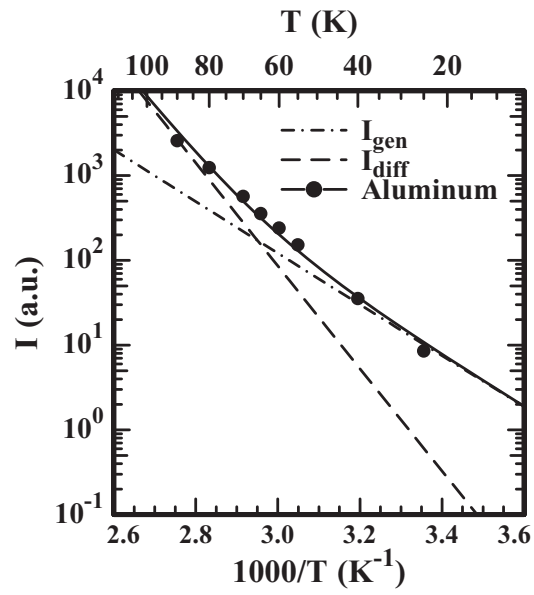

Figure 29. Arrhenius plot of the dark current of a sample contaminated with Al.

be considered as a rough estimate, and it may happen that this estimate is lower than the diffusion current of non-contaminated diodes, though the error bars usually overlap.

We obtained a satisfactory agreement with literature data for the energy levels of slow diffuser contaminants (Mo, W, Ti and V). W is found to increase the diffusion current, in addition to the generation current. Though Mo and W were implanted with very low doses, these elements show a relevant impact on dark current distribution.

Very fast diffusers $(\mathrm{Cu}, \mathrm{Ni})$ probably form precipitate nuclei, or precipitate on pre-existing defects, so their activity is not due to the metal in the solid solution. $\mathrm{Cu}$ contamination has a relevant impact on the dark current distribution, whereas we found a limited impact on the dark current distribution for Ni. Specifically, an increment of the diffusion current is observed for $\mathrm{Cu}$. We tentatively ascribe the increment of the diffusion current to $\mathrm{Cu}$-decoration of the bulk defects.

$\mathrm{Fe}$ and $\mathrm{Cr}$ contamination show no impact of the dark current distributions at the contamination doses and energy under study, however an impact of $\mathrm{Fe}$ contamination is detected by the analysis of the dark current as a function of temperature. No such effect can be detected for $\mathrm{Cr}$ contamination.

The limited impact of $\mathrm{Ni}, \mathrm{Fe}$ and $\mathrm{Cr}$ contamination is probably due to gettering by bulk defects by pairing with boron in the $\mathrm{p}^{+}$substrate. The implantation doses are very close for $\mathrm{Cu}, \mathrm{Ni}, \mathrm{Fe}$ and $\mathrm{Cr}$, so the results obtained for these elements can be compared. According to dark current results, gettering is less effective for $\mathrm{Cu}$ than for $\mathrm{Ni}, \mathrm{Fe}$ and $\mathrm{Cr}$.

Table III. $\Delta \mathrm{E}$ obtained from the best-fit procedure of Eq. 1 to dark current data for various contaminants, and corresponding literature data. $(0,+)$ indicates a donor level, $(0,-)$ indicates an acceptor level and $(+,++)$ indicates a double donor level.

Implantation conditions

\begin{tabular}{c} 
Element \\
\hline- (reference) \\
$\mathrm{Mo}$ \\
$\mathrm{W}$ \\
$\mathrm{Cu}$ \\
$\mathrm{Ni}$ \\
$\mathrm{Fe}$ \\
$\mathrm{Cr}$ \\
$\mathrm{Zn}$ \\
$\mathrm{Ti}$ \\
$\mathrm{V}$ \\
$\mathrm{Al}$
\end{tabular}

$\Delta \mathrm{E}(\mathrm{eV})$

From the best-fit procedure From the literature


Zn shows a limited but appreciable effect. Though $\mathrm{Zn}$ evaporates during the thermal treatments, it is responsible for a mid-gap level, so it is very effective for carrier generation. Thus, even a very small residual $\mathrm{Zn}$ amount can explain the observed dark current contribution.

$\mathrm{Al}$ has a shallow level, hence it is not effective for carrier generation, and no effect of $\mathrm{Al}$ contamination on the dark current distributions is detected.

Finally, we note that the results in Table III confirm our initial assumption that the implantation damage has no relevant effect on the dark current in our experiment. Indeed, some of the elements implanted with the lowest doses have the largest impact (see for instance $\mathrm{W}$ and Mo), whereas $\mathrm{Al}$ as no impact at all, though it was implanted with a relatively high dose.

\section{References}

1. E. R. Fossum, Proceedings of the SPIE - The International Society for Optical Engineering, edited by M. M. Blouke, Vol. 1900, p. 2 (SPIE, 1993).

2. K. Graff, Metal impurities in silicon devices fabrication, Berlin, Springer, 2000

3. D. K. Schroder, IEEE Trans. Electron Devices, 29, p 1336 (1982).

4. W. C. McColgin, J. P. Lavine, J. Kyan, D. N. Nichols, and C. V. Stancampiano, "1992 International Technical Digest on Electron Devices" p. 113 (IEEE, 1992).

5. W. C. McColgin, J. P. Lavine, and C. V. Stancampiano, "Proc.of the 1995 Material Research Society Symposium on Defect and Impurity Engineered Semiconductor and Devices", edited by I. Akasaki, S. Ashok, J. Chevallier, N.M. Johnson, and B.L. Sopori, Vol. 378, p. 713, (Mater. Res. Soc., Pittsburgh, PA, USA, 1996).

6. F. Domengie, J. L. Regolini, D. Bauza, and P. Morin, "Proc. of the 2010 Reliability Physics Symposium", p. 259 (IEEE, 2010)

7. F. Domengie, J. L. Regolini, and D. Bauza,, J. of Electronic Materials, 39, 625 (2010)

8. J. F. Ziegler, M.D. Ziegler, and J.P. Biersack, Nuclear Instruments and Methods in Physics Research B 268, 1818 (2010) http://www.srim.org/.

9. S. Libertino, S. Coffa, C. Spinella, A. La Magna, and V. Privitera, Nuclear Instrument and Methods in Physics Research B 178, 25 (2001).

10. P. A. Stolk, H.-J. Gossmann, D. J. Eaglesham, D. C. Jacobson, C. S. Rafferty, G. H. Gilmer, M. Jaraíz, J. M. Poate, H. S. Luftman, and T. E. Haynes, J. Appl. Phys. 81, 6031 (1997).

11. M. L. Polignano, D. Codegoni, A. Galbiati, S. Grasso, I. Mica, G. Moccia G. Nardone, and F. Russo, ECS Journal of Solid State Science and Technology, 5, 3048 (2016)

12. A. El Gamal and H. Eltoukhy, IEEE Circuits and Devices Magazine, 21, 6 (2005).

13. Sentaurus Device User Guide, Synopsys, Mountain View, CA, USA, 2016

14. A. Poyai, E. Simoen, and C. Claeys, IEEE Trans. on Electron Devices 48, 2445 (2001).

15. J. L. Benton, D. C. Jacobson, B. Jackson, J. A. Johnson, T. Boone, D. J. Eaglesham, F. A. Stevie, and J. Becerro, J. Electrochem. Soc., 146, 1929 (1999).

16. F. Russo, G. Moccia, G. Nardone, R. Alfonsetti, G. Polsinelli, A. D'Angelo, A. Patacchiola, M. Liverani, P. Pianezza, T. Lippa, M. Carlini, M.L. Polignano, I. Mica, E. Cazzini, M. Ceresoli, and D. Codegoni, Solid-State Electronics, 91, 91 (2014)
17. Y. Fujisaki, T. Ando, H. Kozuka, and Y. Takano, J. Appl. Phys. 63, 2304 (1988).

18. S. Boughaba and D. Mathiot, J. Appl. Phys. 69, 278 (1991).

19. M.L. Polignano, I. Mica, F. Barbarossa, A. Galbiati, S. Grasso, and V. Soncini, Nuclear Instruments and Methods in Physics Research B, 356-357, 164 (2015).

20. J. S. Kang and D. K. Schroder, Phys. Stat. Sol. (a), 89, 13 (1985).

21. M.L. Polignano, A. Galbiati, S. Grasso, and I.Mica D.Magni, ECS Journal of Solid State Science and Technology 5, P203 (2016)

22. A.A. Istratov and E. W. Weber, Appl.Phys. A 66, 123 (1998)

23. M. L. Polignano, F. Cazzaniga, A. Sabbadini, F. Zanderigo, and F. Priolo, Mat. Sci. in Semiconductor Processing 1, 119 (1998).

24. W.K. Tice and T. Y. Tan, Appl. Phys. Lett. 28, 564 (1976).

25. R. Hoelzl, K. J. Range, and L. Fabry, Applied Physics A 75, 591 (2002)

26. R. Hoelzl, K. J. Range, and L. Fabry, Applied Physics A 75, 525 (2002).

27. S.D. Brotherton, J.R. Ayres, and A. Gill, J. Appl. Phys. 62, 1826 (1987)

28. H. H. Busta and H. A. Waggener, J. Electrochem. Soc. 124, 1424 (1977).

29. H. Kitagawa and H. Nakashima, Japanese Journal of Appl. Phys. 28, 305 (1989).

30. R. Hoelzl, K. J. Range, and L. Fabry, Applied Physics A 74, 35 (2002).

31. R. Hoelzl, K. J. Range, and L. Fabry, Applied Physics A, 74, 711 (2002).

32. M. L. Polignano, P. Bacciaglia, D. Caputo, C. Clementi, B. Padovani, F. Priolo, and T. Simpson, Proc. of the 7th Electrochemical Society Symposium on High Purity Silicon, , edited by C. L. Claeys, M. Watanabe, P. Rai-Choudhury, and P. Stallhofer, PV 2002-20, p.206 (The Electrochemical Society, 2002).

33. C.-C. Wang, C.-J. Lin, and M.-C. Chen, J. Electrochem. Soc., 150, G557 (2003).

34. M. Tsuchiaki, K. Ohuchi, and C. Hongo, Jpn. J. Appl. Phys., 43, 5166 (2004).

35. M. Tsuchiaki and A. Nishiyama, Jpn. J. Appl. Phys., 46, 1830 (2007).

36. M. Miyazaki, M. Sano, S. Sumita, and N. Fujino, Jpn. J. Appl. Phys., 30, L295 (1991).

37. M. L. Polignano, E. Bellandi, D. Lodi, F. Pipia, A. Sabbadini, F. Zanderigo, G. Queirolo, and F. Priolo, Mat. Sci. Eng. B 55, 21 (1998)

38. S.D. Brotherton, P. Bradley, and A. Gill, J. Appl. Phys. 57, 1941 (1985)

39. M. L. Polignano, G. F. Cerofolini, H. Bender, and C. Claeys, J. Appl. Phys. 64, 869 (1988).

40. L. Baldi, G. Cerofolini, and G. Ferla, J. Electrochem. Soc. 127, 164 (1980).

41. S. M. Myers, M. Seibt, and W. Schröter, J. Appl. Phys. 88, 3795 (2000).

42. R. Hoelzl and M. Blietz, , L. Fabry and R.Schmolke, in Semiconductor Silicon 2002, edited by H. R. Huff, L. Fabry, and S. Kishino, PV 2002-2, p. 608 (The Electrochemical Society, 2002).

43. J. Zhu, D. Barbier, L. Mayet, M. Gavand, and G. Chaussemy, Appl. Surf. Sci. 36, 413 (1989).

44. H. Conzelmann, K. Graff, and E. R. Weber, Appl. Phys. A 30, 169 (1983)

45. M. L. Polignano, D. Caputo, F. Cerutti, M. Cottini, L. Farini, and J. Reffle, Solid State Phenomena. 103-104, 227 (2005).

46. A. Rohatgi, J. R. Davis, R. H. Hopkins, P. Rai-Choudhury, and P.G. McMullin, Solid-State Electron. 23, 415 (1980).

47. H. Lemke, Phys Status Solidi A 64, 549 (1981).

48. A. Nutsch, H. Shimizu, A. Englmüller, and L. Fabry, Proc. of the 2003 IEEE Int. Symp. On Semicond. Manuf. (ISSM), p. 229 (IEEE, 2003).

49. W. Kern, in Handbook of Semiconductor Wafer Cleaning Technology, edited by W. Kern, ch. 1, (Noyes Publications, Park Ridge, NJ, USA, 1993).

50. G. Galvagno, F. La Via, M.G. Saggio, La Mantia A, and E. Rimini, J. Electrochem. Soc. 142, 1585 (1995). 